\title{
The IMPACt of MENINGITIS ON THE Motor Function OF Adult SURVIVORS IN HARARE, ZimbabWE.
}

\begin{abstract}
Objective: The study aimed to document the spectrum of motor impairments and the degree of functional limitation of those who survived adult meningitis and to identify which factors were associated with a poor functional outcome and mortality.
\end{abstract}

Methods: A prospective study was undertaken in the central hospitals in Harare, Zimbabwe. Twenty six adult patients who had survived meningitis were interviewed between one and five months post-admission. Seventeen of these were examined in the clinic for signs of impairment. Nine did not attend the follow-up session and were interviewed at home. The Barthel Activities of Daily Living Index (BI) was administered to all twenty six subjects.

Results: Twenty subjects were HIV sero-positive. Eight subjects died in the time period between the one month interview and the final follow-up five months later. The majority of the seventeen examined in the clinic, demonstrated sensory and motor disturbances. Seven of the twenty six subjects scored eighteen or less on the BI. Forward stepwise logistic regression revealed that a low $B I$ was the only variable which significantly predicted mortality $(p .<0.01)$. The odds of a patient with a low BI dying were 63 times the odds of a patient dying who had a normal Bl.

Discussion and Conclusions: Survivors of meningitis in this study displayed a diversity of impairments and disabilities. Rehabilitation intervention is recommended to provide functional reeducation and support for those with a low BI and to mitigate against the effects of the impairments. A measure of functional disability should be included in the examination of these clients as functional impairment appears to be a predictor of mortality.

KEYWORDS: ADULT MENINGITIS, HIV, IMPAIRMENT, DISABILITY, BARTHEL INDEX.

\section{INTRODUCTION}

The incidence of meningitis in adults is rising in Zimbabwe. Parirenyatwa Hospital, a large central hospital in Harare, recorded a doubling in the number of admissions from 152 in 1993 to 299 in 1995. Meningitis has been associated with the human immunodeficiency virus (HIV) (Petty and Kennedy, 1992). The increase in meningitis may therefore be related to the high prevalence of HIV infection in Zimbabwe, which is estimated to be $17 \%$ of the population, a rate similar to Zambia (17\%) and Botswana (18\%) (Jackson, 1996).

The World Health Organisation (WHO, 1980) developed the concept of classifying the sequelae of disease as impairment,

CORRESPONDENCE:

Jennifer Jelsma, B.Sc.

(Physiotherapy), Dip. Tert. Ed., MPhil Department of Rehabilitation, Faculty of Medicine University of Zimbabwe P.O. Box A178, AVONDALE Harare, Zimbabwe.

Tel: Harare 791631 X 175

Fax: (263) (4) 732828

E-mail: jjelsma@healthnet.zw disability and handicap. Deafness is an impairment that has been described and analysed in paediatric meningitis (Rasmussen et al, 1991). Motor impairments reported in children and adults include cranial nerve involvement, hemiparesis or quadriparesis, muscle hypertonia and ataxia (Feigin et al, 1992; Durand et al, 1993; Kilpi et al, 1993). The severity of focal signs in adult meningitis is not well documented and there is a paucity of information on both the specific patterns of motor impairment and the resulting disability or impact on functional ability. In the light of the evident lack of information relating to the motor sequelae of meningitis in adults and the relatively large number of adults affected, this study was undertaken. The aims of the study were, in a population who survived adult meningitis:

i) to document the spectrum of motor impairments;

ii) to determine the degree of functional limitation or disability ;

iii) to identify which factors predicted a poor functional outcome or death.

\section{METHODS.}

\section{Subjects}

This study formed part of a prospective study of aduIt meningitis conducted from January 1995 to March 1996, the findings of which have been published elsewhere (Heyderman et al, 1996). The subjects were drawn from two hundred consecutive patients older than eight years of age admitted with a laboratory confirmed diagnosis of meningitis over a ten month time period. The two hospitals from which the sample was drawn serve as tertiary referral centres for three quarters of the Zimbabwean population of 11.5 million. The subjects were provisionally recruited on clinical grounds and the diagnosis of meningitis was subsequently confirmed by standard laboratory investigations. The follow-up period lasted five months. The subjects of this paper were those patients that survived up to 30 days post-admission.

\section{Instrumentation}

The Glasgow Coma Scale (Teasdale and Jennet, 1974) and a battery of laboratory tests were applied to confirm the diagnosis of meningitis and determine the HIV status on admission. To maintain 
confidentiality, the results of the HIV tests were only matched with study numbers at the conclusion of the study. The investigators therefore remained blind to the HIV status of the subjects.

An assessment protocol was developed modelled on the WHO classification of impairments (WHO, 1980) to determine the presence and distribution of physical and sensory impairments (see Appendix 1). Two physiotherapists experienced in the management of neurological conditions performed all physical assessments in a private examination room. The first five subjects were assessed by both physiotherapists simultaneously. There was total agreement in scoring of all items except muscle tone. The initial five categories describing tone were replaced with normal, high or low categories. The Barthel Activities of Daily Living Index (BI) (Collin et al, 1988) was used to determine the level of functional disability.

\section{Procedure}

Ethical approval was granted by the Medical Research Council of Zimbabwe.

On admission to hospital the subjects were assessed and managed by the investigating physicians. The Glasgow Coma Scale, tests of cranial nerve function and laboratory tests were applied. One month post-admission, the patients were invited to attend a follow-up clinic. All subjects who attended these clinics were examined by the rehabilitation investigators. Demographic and social data were gathered first, followed by the physical examination and finally the self or attendant's report of abilities as measured on the BI. Defaulters were visited at home by a research assistant who administered the BI but did not examine for motor or sensory impairments. To determine survival rates, patients were followed up for a minimum of five months.

\section{Data Analysis}

Descriptive statistics were used to describe the spectrum of motor and sensory impairments in the subjects. Forward stepwise logistic regression was used to identify which factors increased the likelihood of death. Variables entered into the equation included gender, HIV status, a score of less than 13 on the Glasgow Coma Scale, age, the presence of impairments and a low BI (less than 18/20).

\section{RESIILTS}

Of the 200 patients identified with a confirmed diagnosis of meningitis, 60

\begin{tabular}{|c|c|c|c|c|c|c|c|}
\hline \multicolumn{8}{|c|}{ TABLE 1: CHARACTERISTICS OF THE SUBJECTS ( $\mathrm{N}=26)$} \\
\hline NO. & $\begin{array}{c}\text { AGE } \\
\text { yrs }\end{array}$ & GENDER & $\begin{array}{c}\text { HIV } \\
\text { STATUS }\end{array}$ & $\begin{array}{l}\text { MENINGITIS } \\
\text { ORGANISM }\end{array}$ & GCS & BI & $\begin{array}{c}\text { SURVIVAL } \\
\text { days }\end{array}$ \\
\hline 1 & 24 & male & + & Pyogenic & 14 & 20 & Alive \\
\hline 2 & 41 & male & + & Pyogenic & 14 & 4 & 76 \\
\hline 3 & 40 & male & + & Mononuclear & 14 & 14 & 269 \\
\hline 4 & 32 & male & + & TB Mening. & 15 & 20 & Alive \\
\hline 5 & 33 & female & + & Mononuclear & 14 & 12 & Alive \\
\hline 6 & 65 & female & + & Pyogenic & 11 & 9 & 88 \\
\hline 7 & 34 & male & + & Mononuclear & 13 & 20 & Alive \\
\hline 8 & 25 & male & + & Pyogenic & 14 & 20 & Alive \\
\hline 9 & 35 & female & - & Pyogenic & 14 & 20 & Alive \\
\hline 10 & 26 & female & + & Mononuclear & 15 & 20 & Alive \\
\hline 11 & 30 & male & + & Mononuclear & 13 & 20 & Alive \\
\hline 12 & 60 & male & - & Mononuclear & 14 & 11 & 56 \\
\hline 13 & 45 & female & + & Cryptococcal & 15 & 20 & Alive \\
\hline 14 & 28 & female & + & Cryptococcal & 20 & & 233 \\
\hline 15 & 38 & female & + & Mononuclear & 14 & 9 & 92 \\
\hline 16 & 25 & female & + & Mononuclear & 14 & 20 & Alive \\
\hline 17 & 28 & male & + & Tuberculosis & 15 & 20 & 256 \\
\hline 18 & 18 & male & - & Mononuclear & 10 & 20 & Alive \\
\hline 19 & 38 & female & + & Cryptococcal & 15 & 12 & 90 \\
\hline 20 & 20 & female & + & Pyogenic & 15 & 20 & Alive \\
\hline 21 & 19 & male & - & Pyogenic & 14 & 20 & Alive \\
\hline 22 & 30 & female & + & Mononuclear & 15 & 20 & Alive \\
\hline 23 & 13 & male & missing & Mononuclear & 15 & 20 & Alive \\
\hline 24 & 30 & male & missing & Mononuclear & & 20 & Alive \\
\hline 25 & 28 & male & + & Mononuclear & 14 & 20 & Alive \\
\hline 26 & 45 & female & + & Mononuclear & 15 & 20 & Alive \\
\hline Median & 30 & & & & 14 & 20 & \\
\hline Range & $13-65$ & & & & $10-15$ & $4-20$ & \\
\hline
\end{tabular}

(30\%) survived to one month post-admission and therefore were eligible for inclusion. Of the 60 one month survivors, 26 could be contacted and participated in the study. Seventeen of these attended the clinic and were interviewed by one of the physiotherapists. Nine did not attend and were interviewed at home by the research assistant. The median length of hospital admission was 12 days (range of 2-34 days). Only one subject was still in hospital 30 days post admission and he was seen after discharge. The median time lag to assessment by the rehabilitation team was 70 days (range 28-256 days). Details of the characteristics of the subjects are given in Table 1. There were twelve females and fourteen males. The median age of the subjects was 30 years (range 13-65). Twenty subjects were HIV sero- positive. Two subjects were reported to have had seizures. No subjects had signs of cranial nerve damage.

The seventeen subjects who attended the clinic were tested for motor and sensory impairments. Twelve of the 17 reported a sensory disturbance and motor impairment was detected in 13 cases. Three exhibited moderate auditory impairment. The impairments detected are listed in Table 2. Generalised weakness and muscle wasting were seen in a third of the subjects Fine tremor (seen on holding a position) or intention tremor and abnormal synergies (four) were the most common abnormal movements detected. The sensory impairments reported included partial anaesthesia or numbness (invariably described as "chiwewe" by the subjects), aching and complaints of temperature 
disturbances (the limbs felt hot or cold) and hypersensitivity. The distribution of the sensory losses showed considerable variation, although numbness and pain were reported in the soles of the feet by three subjects.

All 26 cases were tested on the BI and seven cases scored eighteen or less. The major areas of deficit were independent feeding, toileting, and mobility.

The study was terminated five months after recruitment of the final subject. At this stage, eight of the twenty six subjects had died and the median length of survival for the patients who had deceased was 90 days with a range of 56-269 days.

Gender, HIV status, a score of less than 13 on the Glasgow Coma Scale, age and the presence of impairments were not predictive of death. The coefficient of the BI was significantly different from zero $(p<0.01)$ and was thus predictive of mortality. The odds ratio was 63.0 and indicates that the odds of a subject with a low $\mathrm{BI}$ dying were 63 times the odds of a subject dying who had a normal BI score.

\section{DISCUSSION}

The study confirmed that in an adult population with a high rate of HIV seropositivity, adult meningitis leads to considerable morbidity and mortality. A wide diversity of sensory and motor impairments was detected and no uniform site or pattern of neurological damage could be identified. As neurological impairments are commonly associated with both HIV infection (Petty and Kennedy, 1992; Perriens et al, 1992; Amosun et al, 1995) and meningitis (Bohr et al, 1983) it was not possible to separate out the effects of the meningitis from the effects of the underlying HIV infection. However, the spectrum and distribution of impairments were not directly comparable with that reported previously in an adult population with meningitis. For example no patients displayed signs of cranial nerve involvement and only two had seizures in the immediate post-admission phase in comparison with the $27 \%$ cranial nerve involvement and $23 \%$ seizure prevalence in the 445 subjects with bacterial meningitis reported by Durand et al (1993). Similarly, auditory deficits a sequel described by Bohr et al (1983) were found in relatively few subjects. The impairments in the study population more resembled those documented in subjects with HIV, namely weakness, ataxia, incoordination, pain and paraesthesia (O'Dell et al, 1991; Holmberg et al, 1995). O’Dell and Dillon

\begin{tabular}{|c|c|c|c|c|c|c|}
\hline \multicolumn{7}{|c|}{ TABLE 2: SENSORY AND MOTOR IMPAIRMENT (N=17) } \\
\hline NO. & $\begin{array}{l}\text { MUSCLE } \\
\text { TINE }\end{array}$ & STRENGTH & $\begin{array}{l}\text { ABNORMAL } \\
\text { MOVEMENT }\end{array}$ & $\begin{array}{c}\text { MOTOR } \\
\text { DISTRIBUTION }\end{array}$ & $\begin{array}{l}\text { SENSORY } \\
\text { IMPAIRMENT }\end{array}$ & $\begin{array}{c}\text { SENSORY } \\
\text { DISTRIBUTION }\end{array}$ \\
\hline 1 & NAD & NAD & NAD & $N / A$ & Numbness & One LL \\
\hline 2 & High & Weakness & Apraxia & $\begin{array}{l}\text { All limbs, } \\
\text { Face }\end{array}$ & $\begin{array}{l}\text { Hyper- } \\
\text { sensitivity }\end{array}$ & Bilateral LL \\
\hline 3 & High & NAD & $\begin{array}{l}\text { Abnormal } \\
\text { synergies }\end{array}$ & Hemiplegic & Numbness & One UL \\
\hline 4 & NAD & NAD & NAD & N/A & NAD & N/A \\
\hline 5 & NAD & $\begin{array}{l}\text { General } \\
\text { weakness }\end{array}$ & $\begin{array}{l}\text { Fine } \\
\text { tremor }\end{array}$ & All limbs & $\begin{array}{l}\text { Numbness } \\
\text { pain }\end{array}$ & Soles \\
\hline 6 & NAD & Wasting & $\begin{array}{l}\text { Abnormal } \\
\text { synergies }\end{array}$ & $\begin{array}{l}\text { All limbs, } \\
\text { Face }\end{array}$ & NAD & $N / A$ \\
\hline 7 & NAD & NAD & $\begin{array}{l}\text { Intention } \\
\text { tremor }\end{array}$ & One UL & NAD & $N / A$ \\
\hline 8 & NAD & NAD & $\begin{array}{l}\text { Intention } \\
\text { tremor }\end{array}$ & Both UL & NAD & $N / A$ \\
\hline 9 & NAD & NAD & $\begin{array}{l}\text { Abnormal } \\
\text { synergies }\end{array}$ & Both UL & Temperature & $\begin{array}{l}\text { Limbs } \\
\text { trunk }\end{array}$ \\
\hline 10 & NAD & $\begin{array}{l}\text { General } \\
\text { weakness }\end{array}$ & NAD & All limbs & $\begin{array}{l}\text { Numbness } \\
\text { temperature } \\
\text { ache }\end{array}$ & $\begin{array}{l}\text { Palmar } \\
\text { soles }\end{array}$ \\
\hline 12 & NAD & $\begin{array}{l}\text { General } \\
\text { weakness }\end{array}$ & $\begin{array}{l}\text { Inco- } \\
\text { ordination }\end{array}$ & All limbs & $\begin{array}{l}\text { Tingling } \\
\text { ache }\end{array}$ & All limbs \\
\hline 13 & NAD & NAD & NAD & N/A & $\begin{array}{l}\text { Numbness } \\
\text { ache }\end{array}$ & Soles \\
\hline 15 & High & NAD & $\begin{array}{l}\text { Abnormal } \\
\text { synergies }\end{array}$ & All limbs & $\begin{array}{l}\text { Numbness } \\
\text { temperature }\end{array}$ & One LL \\
\hline 16 & NAD & $\begin{array}{l}\text { General } \\
\text { Weakness }\end{array}$ & $\begin{array}{l}\text { Intention } \\
\text { fine tremor }\end{array}$ & All limbs & Temperature & All limbs \\
\hline 17 & NAD & NAD & $\begin{array}{l}\text { Intention } \\
\text { fine tremor }\end{array}$ & All limbs & Numbness & One UL \\
\hline 18 & NAD & Weakness & NAD & Face & Pain & One UL \\
\hline 20 & NAD & NAD & NAD & $N / A$ & NAD & $N / A$ \\
\hline
\end{tabular}

NAD: Nothing abnormal discovered, LL: Lower limb, UL: Upper limb N/A: Not applicable

(1992) state that peripheral neuropathy is extremely common in HIV infection and the most common aetiology of pain is probably sensory peripheral neuropathy.

The percentage of subjects with limited function on the BI $(27 \%)$ was lower than reported in studies on HIV positive patients (Holmberg et al, 1995; O'Dell et al, 1991), although the areas of functional disability, i.e. mobility and self-care were similar (O'Connell and Levinson, 1991). Regression analysis indicated that a low BI score was the only factor found to predict mortality. It may be argued that this might indicate that the underlying patho- logy is further advanced, however, presence of impairments and a low Glasgow coma scale score on admission, which might also indicate progression of disease, were not predictive of death. The discrepancy between the impact of impairments and that of functional level is due to the fact that many impairments (such as numbness or fine tremor) did not adversely affect function at the time of examination. Functional status would appear to be a more sensitive indicator of prognosis than signs of neurological damage. Further study is needed to establish if mortality is due solely to the underlying pathology or 
whether the loss of independent function contributes towards decreased mobility and consequent secondary complications. It might be that decreased mobility could lead to secondary complications, such as hypostatic pneumonia and pressure sores which hasten the onset of death

Follow-up rehabilitation, counselling and support seem essential for those with a low Bl and their families. There is a variable time from admission to death (56 to 269 days) and a strong likelihood of a deteriorating quality of life during this period. Rehabilitation intervention may mitigate against the effects of certain impairments, muscle weakness particularly (Spence et al, 1990), and courses of exercises may be beneficial both for those with impairments and disabilities. However, in this era of dwindling health resources it must be remembered that "planning the care of patients with HIV disease and AIDS is an exercise in damage limitation... Humane care for patients with HIV must also be balanced with the care needs of other patients" (Kerkhoven, 1995). Clearly, a further prospective study is needed to address the impact of ongoing rehabilitation for a population with dual HIV and meningitis pathology.

The use of a standardised protocol for testing motor and sensory impairment based on the WHO classification (WHO, 1980), resulted in a data set that was reliable, easy to administer and interpret. The $\mathrm{BI}$ has been reported to be robust and reliable (Collin et al, 1988; Wade at al, 1988; Johnston et al, 1992) and for this reason it was the instrument of choice for this study. It was the only instrument that was able to predict mortality. The use of both study instruments is recommended in similar studies to facilitate the gathering of further comparative data.

There were unavoidably weaknesses in the study. As no pre-admission assessment was done, it was not possible to determine how many of the signs had existed prior to the onset of meningitis.

Secondly, the attrition rate was high. Despite follow-up home visits, $57 \%$ of eligible subjects were not examined. Those lost to the study were not found at the addresses given on admission and despite home visits to these addresses could not be traced. A large attrition rate can be expected with a study that draws subjects from a large catchment area and a highly mobile population. The large attrition rate could have resulted in a bias in favour of those that survived for a longer period. Thirdly there was a large variation in the time between admission and examination. The original protocol allowed for an examination at a standard one month post-admission. Due to non-attendance at the one month clinic, it was necessary to extend this period. The subjects were drawn from the high density areas in which many people lodge in one house. There is no easy method of communication apart from post as very few people have their own telephones. Problems with follow-up are a feature of cohort studies and are a particular problem when the subjects are drawn from a large catchment area and a migrant population. It is likely that many subjects, who were not well, left their urban lodgings and returned to their rural area of origin and extended families on discharge. The large number lost to follow-up and the varying length of time from admission to examination were flaws in the study that were unfortunate but unavoidable.

\section{CONCIUSIONS}

It is concluded that the survivors of meningitis in this study displayed a diversity of impairments and disabilities and that these may be related to both menin-

\section{REFERENCES}

Amosun SL, Gatsi LT, Mawere J 1995 Neurological manifestations in AIDS. South African Journal of Physiotherapy 51:45-47

Bohr V, Hansen B, Jessen O, Johnsen N, Kjersem H, Kristensen HS, Nyboe J 1983 Eight hundred and seventy five cases of bacterial meningitis. Part I of a three-part series: Clinical data, prognoses, and the role of specialised hospital departments. Journal of Infection 7: 21-30

Collin C, Wade DT, Davies S, Horne V 1988 The Barthel ADL Index : a reliability study. International Disability Studies 10:61-67

Durand ML, Calderwood SB, Weber DJ, Miller SI, Southwick FS, Caviness VS, Swartz MN 1993 Acute bacterial meningitis in adults : A review of 493 episodes. The New England Journal of Medicine 328:21-28

Feigin RD, McCracken GH, Klein JO 1992 Diagnosis and management of meningitis. $P e$ diatric Infectious Disease Journal 11:785-814

Heyderman RS, Gangaidzo IT, Hakim JG, Mielke J, Taziwa A, Musvaire P, Robertson VJ, Mason PR 1998 Cryptococcal meningitis in human immunodeficiency virus-infected patients in Harare, Zimbabwe. Clinical Infectious Diseases 26 :284-289

Holmberg SD, Buchbinder SP, Conley LJ, Wong LC, Katz M, Pencey KA, Hershon RC, Judson FN 1995 The spectrum of medical conditions and symptoms in homosexual and gitis and the underlying HIV pathology. In addition to neurological tests, a measure of functional disability should be included in the discharge examination as functional impairment appears to be predictive of final outcome

It needs to be established whether rehabilitation intervention can prolong life in these patients, however it is highly likely that the quality of life of such patients could be improved by physiotherapy and in future "primary care providers will increasingly look to rehabilitation medicine for assistance in the management of HIV-related impairment, disability and handicap" (O'Dell and Dillon, 1992). Rehabilitation intervention is therefore recommended to provide functional re-education and support for those with a low BI and to mitigate against the effects of the impairments. However, against a backdrop of severely limited resources, the cost-effectiveness of intervention needs to be established.

\section{ACKNOWLEDGEMENTS}

University of Zimbabwe Research Board for funding, Mr A Taziwa, Sister P Monjoro, Sister E Mushangi. bisexual men infected with HIV. American Journal of Epidemiology 14:395-404

Jackson H 1996 Vancouver: One world, one hope? SAFAIDS News 4: 2-8

Johnston MV, Keith RA, Hinder SR 1992 Measurement standards for interdisciplinary medical rehabilitation. Archives of Physical Medicine and Rehabilitation 71:870-875

Kerkhoven R, Foster S 1995 The cost and burden of AIDS on the Zambian health care system: Policies to mitigate the impact on health services. SAFAIDS News 3:2-5.

Kilpi T, Anttila M, Markku JTK, Peltola H 1993 Length of prediagnostic history related to the course and sequelae of childhood bacterial meningitis. Pediatric Infectious Disease Journal 12:184-8

O'Connell PG, Levinson SF 1991 Experience with rehabilitation in the Acquired Immunodeficiency Syndrome. American Journal of Physical Medicine and Rehabilitation 71; 195-200

O'Dell MW, Crawford A, Bohi ES, Bonner FJ 1991 Disability in Persons Hospitalised with AIDS. American Journal of Physical Medicine and Rehabilitation 71:91-95

Perriens JH, Mussa M, Luabeya MK, Kapita B, Brown C, Piot P, Janssen R 1992 Neurological complications of HIV-1-seropositive internal medicine inpatients in Kinshasa, Zaire. Journal of Acquired Immune Deficiency Syndromes $5: 333-40$ 


\section{- REFERENCES (Continued from page 9)}

Petty RK. Kennedy PG 1992 The neurologica] features of HIV-positive patients in Glasgow a retrospective study of 90 cases. Quarterly Journal of Medicine 299:223-34

Rasmussen N, Johnsen NJ, Bohr VA 199l Otological sequelae after pneumococcal meningitis: A survey of 164 consecutive cases with a follow-up of 94 Survivors. Laryngoscope 101:876-882
Spence DW, Galantino ML, Mossberg KA, Zimmerman SO 1990 Progressive resistance exercise: Effect on muscle function and anthropometry of a select AIDS Population. Archives of Physical Medicine and Rehabilitation 70:644-648

Teasdale C, Jennet WB 1974 Assessment of coma and impaired consciousness. The Lancet ii:8]
Wade DT, Collin C 1988 The Barthel ADL Index: a standard measure of physical disability? International Disability Studies 10:64-67.

WHO. I980 The International Classification of Impairments, Disabilities and Handicaps. WHO Geneva.

\section{APPENDIX 1 \\ ASSESSMENT OF PHYSICAL IMPAIRMENTS \\ Protocol}

Subject in supine on plinth.

Tone:

Test resistance to passive movements, particularly to elbow extension, forearm supination, wrist and finger extension, hip abduction and flexion and extension, knee flexion and dorsi-flexion of the ankle. Perform the movement slowly first and then fast. Test biceps and patella tendon jerks.

\section{Strength:}

Give isometric resistance in middle range to all movements of the shoulder, elbow, wrist, hand, hip, knee and ankle. If subject is unable to sustain the isometric contraction against resistance, regard that movement as being weak.

\section{Abnormal movements:}

Intention tremor: Subject touches with the tip of his finger his/her nose and examiners finger several times.

The examiner varies the position of her finger. The subject puts his/her heel on the opposite knee and runs the heel down the shin to the ankle.

Abnormal synergies: Subject holds arm in shoulder flexion with elbow extension, forearm supination and wrist extension. Watch whether he/she bends elbow and pronates forearm. Subject holds leg in 45 degrees of hip flexion, knee extension and dorsi-flexion. Watch for involuntary hip adduction and plantar flexion.

Fine tremor: Subject points at ceiling. Examiner lightly holds on either side of finger to detect fine tremor. Subject holds lower limb off surface. Examiner touches lightly to detect tremor.

\section{DATA RECORDING FORM}

1. TONE:

1. Normal

2. Increased

3. Decreased

2. TONE DISTRIBUTION:

1. No abnormality

2. Trunk

3. Hemiplegic

4. Paraplegic

5. Quadriplegic

6. Monoplegic

7. Other

\section{MUSCLE STRENGTH:}

1. Normal

2. Wasting

3. Generalised weakness

4. Specific muscle weakness (root or peripheral nerve distribution)

\section{STRENGTH DISTRIBUTION: \\ 1. No abnormality \\ 6. ABNORMAL MOVEMENT DISTRIBUTION:}

2. Trunk

3. Hemiplegic

4. Paraplegic

5. Quadriplegic

6. Monoplegic

7. Other

\section{ABNORMAL} MOVEMENTS:

1. None

2. Intention tremor

3. Resting tremor

4. Abnormal synergies (Upper motor neurone lesion)

5. Choreiform movements

6. Incoordination due to weakness

7. Other
1. No abnormality

2. Trunk

3. Hemiplegic

4. Paraplegic

5. Quadriplegic

6. Monoplegic

7. Other

\section{SENSORY DISTURBANCE/LOSS}

1. None

2. Numbness

3. Tingling

4. Itching

5. Ache/pain

6. Abnormal Temperature sensations (hot/cold)

7. Other

\section{SENSORY DISTURBANCE DISTRIBUTION:}

1. No abnormality

2. Trunk

3. Hemiplegic

4. Paraplegic

5. Quadriplegic

6. Monoplegic

7. Soles of feet

8. Palms of hands

9. Other 